\title{
EFEITO DA HETEROSE NA QUALIDADE DE SEMENTES DE MILHO DOCE ${ }^{1}$
}

\author{
LUCILÉA SILVA DOS REIS², MESSIAS GONZAGA PEREIRA ${ }^{3}$, ROBERTO FERREIRA DA SILVA ${ }^{3}$, \\ ROBSON CELESTINO MEIRELES ${ }^{4}$
}

\begin{abstract}
RESUMO - Este trabalho teve por objetivo avaliar a qualidade fisiológica das sementes de genótipos selecionados de milho doce e sua relação com a heterose. Foram utilizados 14 genótipos de milho doce desenvolvidos pela Universidade Estadual do Norte Fluminense Darcy Ribeiro. Os genótipos foram multiplicados no município de Campos dos Goytacazes por meio de polinização controlada para assegurar a pureza genética. A qualidade fisiológica foi avaliada por meio do teste de germinação e dos seguintes testes de vigor: primeira contagem de germinação, classificação de plântulas e emergência em areia. Pelos resultados é possível concluir que as sementes de endosperma doce foram menos vigorosas que as sementes de endosperma comum. $\mathrm{O}$ emprego de genótipos parentais adaptados à região de plantio proporcionou melhor vigor às sementes de endosperma doce, quando comparado ao uso de parentais não adaptados. Para todas as características avaliadas de germinação e vigor observou-se heterose nas sementes híbridas em relação aos seus parentais. O desenvolvimento de híbridos pode ser uma excelente alternativa para a obtenção de sementes de milho doce vigorosas e de qualidade fisiológica superior.
\end{abstract}

Termos para indexação: heterose, milho doce, sementes.

\section{EFFECT OF HETEROSIS ON SWEET CORN SEEDS QUALITY}

\begin{abstract}
The objective of this study was to evaluate the physiological seed quality of selected sweet corn genotypes and their relationship to heterosis. Fourteen sweet corn genotypes developed by the Universidade Estadual do Norte Fluminense Darcy Ribeiro were used. The genotypes were multiplied in Campos dos Goytacazes through controlled pollination to ensure genetic purity. The physiological quality was evaluated using germination and vigor tests, including: first germination count and seedling classification and emergence in sand. Results showed that the seeds with sweet endosperm were less vigorous than those with common endosperm. The sweet endosperm seeds of parental genotypes adapted to the region were more vigorous than those of non-adapted parents. Heterosis was observed for all germination and vigor traits in hybrid seeds when compared to their parents. Results indicate that hybrid development has an excellent potential for obtaining strong and more vigorous sweet corn seeds.
\end{abstract}

Index terms: heterosis, sweet corn, seeds.

\footnotetext{
${ }^{1}$ Submetido em 25/09/2009. Aceito para publicação em 23/10/2010. Parte de tese de Doutorado do primeiro autor em Genética e Melhoramento de Plantas pela Universidade Estadual Norte Fluminense Darcy Ribeiro

${ }^{2}$ Doutora em Genética e Melhoramento de plantas - UENF -Profa.IFESSanta Teresa.lucileasr@ifes.edu.br
}

${ }^{3}$ Professor Departamento de Fitotecnia - UENF, messias@uenf.br; roberto@uenf.br

${ }^{4}$ Doutor em Produção Vegetal - Prof. IFES - Santa Teresa, robsoncm@
ifes.edu.br 


\section{INTRODUÇÃO}

Em áreas próximas a grandes centros urbanos, o milho doce, em razão de suas características agronômicas, pode obter preços diferenciados no mercado, principalmente pelo caráter doce do seu endosperma. De consumo diversificado, este milho especial pode ser utilizado em conserva, congelado na forma de espigas ou grãos, desidratado, consumido "in natura", ou usado como "baby corn", ou minimilho, quando colhido antes da polinização. Após a colheita, a palhada da cultura pode ser utilizada para ensilagem (Souza et al., 1990).

O milho doce difere do milho comum por possuir genes mutantes, que desencadeiam mudanças na sua qualidade, no aspecto da planta e na viabilidade da semente (Gama et al., 1992). Na fase de grãos leitosos, seus grãos são tenros e possuem maior quantidade de sacarose, dextrinas e vitaminas, em relação ao milho verde comum (Storck; Lovato 1991).

As pesquisas realizadas com milho doce, de uma maneira geral, têm demonstrado qualidade inferior de suas sementes, possivelmente devido à maior sensibilidade e suscetibilidade aos danos físicos e àqueles decorrentes das suas alterações bioquímicas. Segundo Waters-Jr.; Blanchette (1983), a menor porcentagem de emergência das plântulas no milho doce ocorre em função do manuseio incorreto das sementes e, ainda, de outros fatores que causam a redução da sua qualidade. Não está completamente esclarecido se o baixo vigor das sementes do milho doce é consequência da menor reserva de amido no endosperma, ou do fato de o embrião ser, por si mesmo, geneticamente inferior e incapaz de exibir um alto vigor (McDonald et al.,1994).

Elevados teores de açúcares solúveis, baixo teor de reservas no endosperma e pericarpo tenro são características de sementes de milho doce que, por isso, têm rápida perda da viabilidade e são mais suscetíveis a danos e à entrada de patógenos (Guiscem et al., 2002).

Novas cultivares de milho doce têm sido criadas por programas de melhoramento genético. Tais cultivares, além de adaptadas a determinadas condições edafoclimáticas, produzem sementes com qualidade fisiológica e grãos com características industriais desejáveis. Gomes et al., (2000) observaram ganho genético na qualidade fisiológica de sementes de milho comum, durante o processo de melhoramento.

Na cultura do milho (Zea mays L.), a demanda por sementes híbridas, com alta qualidade, tem aumentado significativamente nos últimos anos, devido, principalmente, à alta competitividade do mercado, fazendo com que as empresas produtoras de sementes adotem, muitas vezes, padrões de qualidade mais rígidos do que os estabelecidos por órgãos oficiais (Gomes et al., 2000).

O alto desempenho dos híbridos de milho é resultado do efeito heterótico alcançado pelo cruzamento de linhagens que possuem boa capacidade combinatória. Em geral, o principal efeito esperado está relacionado com o aumento do rendimento (Allard, 1971). Apesar de vários caracteres agronômicos serem melhorados e explorados através da heterose, as bases do vigor híbrido, para qualidade fisiológica de sementes não estão totalmente elucidadas. No entanto, o envolvimento de hormônios, como as auxinas (Tafuri, 1966) e giberelinas (Rood et al., 1983 e 1990), parece evidente.

$\mathrm{O}$ vigor híbrido em relação à taxa de crescimento e ao potencial de produção pode estar associado com a alta atividade fisiológica e bioquímica das plantas $\mathrm{F}_{1}$ híbridas (Srivastava,1983 e McDaniel, 1986). Mino e Inoue (1994) reportaram que o vigor híbrido, manifestado pela rápida germinação e crescimento vigoroso de plântulas, está associado com altas taxas de metabolismo de RNA, proteínas, lipídeos, DNA e glicose nos embriões.

Segundo Pereira et al. (2008), é possível buscar características que possibilitem maior qualidade fisiológica, maior vigor e melhor desempenho das sementes e, por conseguinte, uniformidade na emergência para a produção das plantas em condições de campo. Essas características normalmente não têm sido avaliadas em programas de melhoramentos de milho comum. Mas, para a cultura do milho doce, espera-se que seja possível identificar genótipos com bom desempenho agronômico, associado à qualidade fisiológica de sementes.

Deste modo, o objetivo desse trabalho foi avaliar a qualidade fisiológica das sementes dos genótipos de milho verde utilizados no programa de melhoramento de milho doce da Universidade Estadual do Norte Fluminense Darcy Ribeiro, buscando identificar possíveis efeitos heteróticos em características como germinação e vigor.

\section{MATERIAL E MÉTODOS}

O experimento foi desenvolvido na área experimental 
e no Laboratório de Análise de Sementes do Centro de Ciências e Tecnologias Agropecuárias (CCTA) da Universidade Estadual do Norte Fluminense Darcy Ribeiro. Foram multiplicados 14 genótipos, entre testemunhas, genitores e híbridos, conforme tabela 1 . O campo de produção de sementes foi instalado na área experimental da Escola Técnica Estadual Agrícola Antônio Sarlo, no município de Campos dos Goytacazes, região norte do estado do Rio de Janeiro.

TABELA 1. Genótipos multiplicados para avaliação da qualidade fisiológica das sementes.

\begin{tabular}{cl}
\hline Tratamento & \multicolumn{1}{c}{ Genótipo } \\
\hline 1 & Doce de Cuba / Piranão \\
2 & Doce de Cuba / Cimmyt \\
& Doce de Cuba / Piranão X Doce de Cuba / \\
3 & Cimmyt \\
4 & 43 In / Piranão \\
5 & 43 In / Cimmyt \\
6 & 43 In / Piranão X 43 In /Cimmyt \\
7 & Piranão 8 \\
8 & Cimmyt 8 \\
9 & Uenf - 506 - 8 \\
10 & Br 401 \\
11 & 43 In / L 154 B X 43 In / L B 73 \\
12 & Doce de Cuba / L 154 B X Doce de Cuba \\
13 & Br B 73 \\
14 & Br 400 \\
\hline
\end{tabular}

Para a obtenção do material e evitar cruzamentos indesejados as espigas foram cobertas com sacolas plásticas antes da emissão dos estigmas e, de modo concomitante, os pendões foram cobertos com sacolas de papel de modo a evitar a contaminação por pólen estranho. Buscando a obtenção de sementes de pureza genética assegurada, além dos cruzamentos controlados, o plantio sofreu isolamento no tempo e no espaço.

Logo após os procedimentos de colheita e secagem, as espigas foram debulhadas e as sementes homogeneizadas para uniformização e posterior avaliação da qualidade. A qualidade fisiológica das sementes foi avaliada por meio dos seguintes testes:

Germinação - Foram utilizadas oito repetições de 50 sementes que foram dispostas sobre folhas de papel germitest utilizadas como substrato. Essas folhas foram previamente umedecidas com água destilada, na proporção de duas vezes e meio o peso do papel seco. Após a semeadura, os rolos de papel foram colocados em sacos plásticos de polietileno para um melhor controle da umidade e, em seguida, levados a câmara do tipo BOD regulada com temperatura alternada de $25{ }^{\circ} \mathrm{C}$ por um período de sete dias, data da última avaliação (Brasil, 1992).

Primeira Contagem de germinação - $\mathrm{O}$ vigor das sementes determinado por meio da primeira contagem foi obtido em conjunto com o teste de germinação, de modo que a avaliação foi executada ao se completarem quatro dias transcorridos da semeadura. Os resultados foram expressos em porcentagem (Brasil, 1992).

Classificação de plântulas - Ao término do teste de germinação, as plantas oriundas do mesmo foram classificadas quanto ao seu vigor, em fortes, fracas e anormais, conforme Brasil (1992).

Índice de velocidade de germinação - Foi realizado de maneira análoga ao teste de germinação, fazendo-se a contagem diária, a partir do quarto dia após a semeadura, do número de plântulas que atingiram o comprimento mínimo de $4 \mathrm{~cm}$ de parte aérea e $10 \mathrm{~cm}$ de radícula, até a estabilização. Posteriormente, foi determinado o índice de velocidade de germinação por meio da expressão proposta por Edmond; Drapala (1958):

$$
\mathrm{M}=\frac{(\mathrm{N} 1 \times \mathrm{G} 1)+(\mathrm{N} 2 \times \mathrm{G} 2)+\ldots+(\mathrm{Nn} \times \mathrm{Gn})}{\mathrm{G} 1+\mathrm{G} 2+\ldots+\mathrm{Gn}} \text {, onde: }
$$

M: número médio de dias para germinação;

N1: número de dias para a primeira avaliação;

G1: número de sementes germinadas na primeira avaliação;

Nn: número de dias para a última avaliação;

Gn: número de sementes germinadas na última avaliação.

Índice de velocidade de emergência - foi determinado segundo Edmond; Drapala (1958), anotando-se o número de plântulas com mais de $2 \mathrm{~cm}$ de comprimento emergidas a cada dia, a partir da data do início da emergência até a completa estabilização do estande.

Os experimentos relativos à análise de sementes foram desenvolvidos no delineamento inteiramente casualizado e os resultados obtidos submetidos a testes de normalidade e análise de variância, bem como teste de 
Tukey (5\%) para comparação entre médias.

Para avaliação dos genitores e combinações híbridas, foi realizado o cálculo da estimativa da heterose (\%), comparando-se cada híbrido com a média de seus pais, por meio da expressão:

Heterose $(\%)=\underline{\text { Média do híbrido }- \text { Média dos Pais }}$ x100

Média dos Pais

\section{RESULTADOS E DISCUSSÃO}

$\mathrm{Na}$ Tabela 2 encontram-se os resultados de germinação de todos os genótipos estudados. Os genótipos de milho comum apresentaram geminação superior aos genótipos de milho doce, contudo, os genótipos de milho doce de origem 43IN, seguido do de origem Doce de Cuba oriundos de genitores recorrentes adaptados apresentaram boa germinação em relação às testemunhas e demais genótipos.

Ao se avaliar o vigor das sementes pelo teste de primeira contagem de germinação (Tabela 3), observa-se a formação de três grupos distintos de qualidade, sendo o primeiro formado pelos genitores e híbridos de milho comum adaptado, o segundo formado pelos genitores e híbridos de milho doce cujos genitores recorrentes também foram genótipos adaptados e, um terceiro grupo formado pelas testemunhas comerciais doces.

TABELA 2. Estimativa de heterose (\%) em função da germinação (\%) de sementes de diferentes de genótipos de milho doce.

\begin{tabular}{lcc}
\hline \multicolumn{1}{c}{ Genótipo } & Germinação (\%) & H (\%) \\
\hline DOCE DE CUBA / PIRANÃO & 76,43 & \\
DOCE DE CUBA / CIMMYT & 78,97 & 12,56 \\
DOCE DE CUBA / PIRANÃO X DOCE DE CUBA / CIMMYT & $87,46 \mathrm{~b}$ & 15,62 \\
43IN / PIRANÃO & 76,48 & \\
43IN / CIMMYT & 78,96 & 4,39 \\
43IN / PIRANÃO X 43IN /CIMMYT & $89,84 \mathrm{~b}$ & \\
PIRANÃO 8 & 92,67 & \\
CIMMYT 8 & 93,25 & \\
UENF - 506 - 8 & $97,05 \mathrm{a}$ \\
BR 401 & 74,67 & \\
43IN / L154b X 43IN / LB73 & 67,89 & \\
DOCE DE CUBA / L154b X DOCE DE CUBA / LB73 & 68,42 \\
BR 400 & 70,08 \\
BR 402 & 65,34 \\
\hline CV (\%) & 6,34 \\
\hline
\end{tabular}

Médias seguidas pela mesma letra não diferem entre si pelo teste de Tukey a $5 \%$ de probabilidade.

Wann (1980) expõe que o baixo vigor das sementes de milho doce possivelmente está ligado ao tamanho do endosperma, sugerindo que, embora o vigor seja uma característica fortemente relacionada com o embrião, a menor quantidade de reservas dessas sementes pode afetar o vigor e, o aumento da proporção endosperma/embrião tende a ser vantajoso para a melhoria da qualidade das sementes.

Os resultados referentes à velocidade de germinação e emergência (tabela 3) também mostram a mesma tendência nos dados, ou seja, sementes de endosperma amiláceo foram mais vigorosas que as sementes de endosperma doce.

Contudo, ao se avaliar o vigor pelo teste de classificação de plântulas (tabela 3), verifica-se que os híbridos doces 43IN e Doce de Cuba, provenientes de genitores recorrentes adaptados (Cimmyt e Piranão) não diferiram dos genótipos de milho comum. O que indica que as sementes de milho doce germinam de maneira mais lenta que o milho comum, 
porém essa velocidade, em condições de laboratório, não interferiu na qualidade das plântulas. Entretanto, a velocidade de germinação é condição determinante do bom estabelecimento da cultura no campo, podendo interferir no estande final, uma vez que o maior tempo no solo pode favorecer o ataque de pragas e microrganismos.

TABELA3. Estimativa de heterose (\%) em função do vigor determinado pela primeira contagem de germinação (\%), plântulas fortes (\%), índice de velocidade de germinação (IVG) e índice de velocidade de emergência (IVE) de sementes de diferentes de genótipos de milho doce.

\begin{tabular}{|c|c|c|c|c|c|c|c|c|}
\hline Genótipo & $\begin{array}{c}\text { Primeira } \\
\text { contagem }(\%)\end{array}$ & $\mathrm{H}(\%)$ & $\begin{array}{l}\text { Plântulas } \\
\text { fortes (\%) }\end{array}$ & $\mathrm{H}(\%)$ & IVG & $\mathrm{H}(\%)$ & IVE & $\mathrm{H}(\%)$ \\
\hline $\begin{array}{l}\text { DOCE DE CUBA / } \\
\text { PIRANÃO }\end{array}$ & 63,56 & & 76,09 & & 6,45 & & 14,22 & \\
\hline $\begin{array}{l}\text { DOCE DE CUBA / } \\
\text { CIMMYT }\end{array}$ & 62,45 & & 73,21 & & 6,34 & & 13,89 & \\
\hline $\begin{array}{l}\text { DOCE DE CUBA / } \\
\text { PIRANÃO X DOCE DE } \\
\text { CUBA / CIMMYT }\end{array}$ & $72,23 b$ & 14,65 & $86.98 \mathrm{a}$ & 16,51 & $5.02 \mathrm{~b}$ & $-21,43$ & $13,34 b$ & $-5,05$ \\
\hline 43IN / PIRANÃO & 64,76 & & 74,46 & & 5,67 & & 14,48 & \\
\hline 43IN / CIMMYT & 68,23 & & 76,42 & & 6,69 & & 13,34 & \\
\hline $\begin{array}{l}\text { 43IN / PIRANÃO X 43IN } \\
\text { /CIMMYT }\end{array}$ & $77,45 b$ & 16,48 & $88,02 \mathrm{a}$ & 16,67 & $4,48 \mathrm{a}$ & $-27,5$ & $12,02 b$ & $-13,58$ \\
\hline PIRANÃO 8 & 86,42 & & 78,01 & & 4,67 & & 10,45 & \\
\hline CIMMYT 8 & 87,25 & & 75,02 & & 4,89 & & 9,78 & \\
\hline UENF $-506-8$ & $91,34^{\mathrm{a}}$ & 5,19 & $89,46 a$ & 16,92 & $4,56 \mathrm{a}$ & $-4,61$ & $9,37 \mathrm{a}$ & $-7,31$ \\
\hline BR 401 & 55,45 & & 56,88 & & 6,78 & & 14,68 & \\
\hline $\begin{array}{l}43 \mathrm{IN} / \mathrm{L} 154 \mathrm{~b} \text { X 43IN / } \\
\text { LB73 }\end{array}$ & 57,78 & & 54,78 & & 6,02 & & 13,56 & \\
\hline $\begin{array}{l}\text { DOCE DE CUBA / L154b } \\
\text { X DOCE DE CUBA / } \\
\text { LB73 }\end{array}$ & 58,45 & & 54,23 & & 6.56 & & 13,44 & \\
\hline BR 400 & 54,67 & & 50,34 & & 6,47 & & 13,89 & \\
\hline BR 402 & 58,92 & & 55,89 & & 6,25 & & 13,89 & \\
\hline $\mathrm{CV}(\%)$ & 5,78 & & 7,56 & & 7,89 & & 7,46 & \\
\hline
\end{tabular}

Médias seguidas pela mesma letra não diferem entre si pelo teste de Tukey a 5\% de probabilidade.

Para todas as características avaliadas de germinação e vigor observou-se efeito heterótico nas sementes híbridas em relação aos seus parentais (Tabelas 2 e 3 ), indicando que o desenvolvimento de híbridos pode ser uma excelente alternativa para a obtenção de sementes de milho doce mais vigorosas, capazes de estabelecer plantios formados por plantas normais. Gomes et al. (2000), também encontraram efeitos heteróticos sobre a germinação e vigor de sementes de milho, verificando que nessa espécie as sementes híbridas apresentam maior vigor que seus parentais.
É válido ressaltar que no caso do híbrido 43IN, oriundo de genitores recorrentes adaptados (Cimmyt e Piranão), seguido do Doce de Cuba nas mesmas condições, apresentaram heterose superior à encontrada no híbrido comum UENF-506-8, indicando efeito residual benéfico do genoma do doador sobre o vigor das sementes.

\section{CONCLUSÃO}

As sementes de endosperma doce são menos vigorosas que as sementes de endosperma normal, sendo que os 
parentais adaptados à região proporcionam melhor vigor às sementes de endosperma doce, quando comparados aos parentais não adaptados. A heterose presente nas sementes híbridas de milho doce possibilita a melhoria da germinação e do vigor em relação aos seus parentais.

\section{REFERÊNCIAS}

\begin{abstract}
ALLARD, R.W. Princípios do melhoramento genético em plantas. São Paulo: Ed. Blucher, 1971. 381p.
\end{abstract}

BRASIL. Ministério da Agricultura e Reforma Agrária. Secretaria Nacional de Defesa Agropecuária. Departamento Nacional de Produção Vegetal. Coordenação de Laboratório Vegetal. Regras para Análise de Sementes. Brasília, DF, 1992. 365p.

EDMOND, J.B.; DRAPALA, W.J. The effects of temperature, sand and soil, and acetone on germination of okra seeds. Proceedings of American Society Horticultural Science, v.71, p.428-434, 1958.

GAMA, E.E.G.; PARENTONI, S.N.; REIFCHNEIDER, F.J.B. Origem e importância do milho doce. In: EMBRAPA. Centro Nacional de Pesquisa de Milho e Sorgo (Sete Lagoas, MG). A cultura do milho doce. Sete Lagoas, 1992. p.5-7. (Embrapa-CNPMS. Circular técnica n, 18).

GOMES, M.S.; VON PINHO, E.V.R.; VON PINHO, R.G.; VIEIRA, M.G.G.C. Efeito da heterose na qualidade fisiológica de sementes de milho. Revista Brasileira de Sementes, v.22, n.1, p.7-17, 2000.

GUISCEM, J.M.; NAKAGAWA, J.; ZUCARELI, C. Qualidade fisiológica de sementes de milho-doce BR 400 (BT) em função do teor de água na colheita e da temperatura de secagem. Revista Brasileira de Sementes, v.24, n.1, p. 220-228, 2002.

McDANIEL, R.G. Biochemical and physiological basis of heterosis. Critical Reviews of Plant Science, v.30, n.1, p. 227-246, 1986.

MINO, M.; INOUE, M. Analysis of glucose metabolism in the heterotic viability in seedling growth of maize F1 hybrid. Japan Journal Crop Science, v. 63, n. 4, p. 682688, 1994.

MCDONALD, M.B.; SULLIVAN, J.; LAWER, M.J. The pathway of water uptake in maize seeds. Seed Science and Technology, v.22, n.1, p. 79-90, 1994.

PEREIRA, A.F.; MELO, P.G.S.; OLIVEIRA, J.P.; ASSUNÇÃO, A.; BUENO, L.G. Qualidade fisiológica de sementes e desempenho agronômico de milho doce. Pesquisa Agropecuária Tropical, v.4, n.38, p.249-261, 2008.

ROOD, S.B.; BLAKE, T.J.; PHARIS, R.P. Gibberellins and heterosis in maize. Response to gibberellic acid and metabolism of of $\left[{ }^{3} \mathrm{H}\right] \mathrm{GA}_{20}$. Plant Physiology, v.71, n.3, p.645-651, 1983.

ROOD, S.B.; BUZZELL, R.I.; MAJOR, D.J. Gibberellins and heterosis in maize: quantitative relationships. Crop Science, v.30, n.2, p. 281-286, 1990.

SOUZA, I.R.P.; MAIA, A.H.N.; ANDRADE, C.L.T. Introdução e avaliação de milho doce na região do baixo Paranaíba. Parnaíba: EMBRAPA-CNPAI, 1990. 7p.

SRIVASTAVA, H.K. Heterosis and intergenomic complementation: Mitochondria, chloroplast and nucleus. In: Monographs on theorotical and applied genetics. Berlim: Springer-Verlag, v.6, p.260-286, 1983.

STORK, L.; LOVATO, C. Milho doce. Ciência Rural, v.21, n.2, p.283-292, 1991.

TAFURI, F. IAA. Determination in the kernels of four lines of corn and their hybrids. Phytochemistry, v.5, n.4, p. 999-1003, 1966.

WANN, E.V. Seed vigor and respiration of maize kernels with different endosperm genotypes. Journal of the American Society for Horticultural Sciences. v.96, p.441-444, 1980.

WATERS JR, L.; Blanchette, B. Prediction of sweet corn field emergence by conductivity and cold tests. Journal of the American Society for Horticultural Sciences. v.108, p.778-781, 1983. 